\title{
Long-Term Radiotoxicity Evaluation of PWR Spent Uranium and MOX Fuel and Highly Active Waste
}

\author{
Petar Paunov ${ }^{1}$ and Ivaylo Naydenov $2^{2 *}$ \\ ${ }^{1}$ Kozloduy NPP, Kozloduy, Bulgaria \\ ${ }^{2}$ Scientific and Technical Union of Power Engineers in Bulgaria, Sofia 1000, Bulgaria
}

\begin{abstract}
One of the main concerns related to nuclear power production is the generation and accumulation of spent nuclear fuel. Currently most of the spent fuel is stored in interim storage facilities awaiting final disposal or reprocessing. The spent fuel is stored in isolation from the environment in protected facilities or specially designed containers. Nevertheless, spent fuel and highly active waste might get in the environment in case the protective barriers are compromised. In such a case, spent fuel may pose risk to the environment and human health. Those risks depend on the concentration of the given radionuclide and are measured by the value of potential danger. The potential danger is called also 'radiotoxicity'. The paper examines spent uranium and MOX fuels from a reference PWR, as well as the highly radioactive wastes of their reprocessing. The radiotoxicity of the four materials is examined and evaluated for a cooling time of 1000 years. The contribution of different radionuclides is assessed and the cases of reprocessing and no reprocessing of spent fuel have been compared.
\end{abstract}

\section{Introduction}

One of the main concerns related to nuclear power production is the generation and accumulation of spent nuclear fuel. Currently most of the spent fuel is stored in interim storage facilities awaiting final disposal or reprocessing. The spent fuel is stored in isolation from the environment in protected facilities or specially designed containers [1]. Nevertheless, spent fuel and highly active waste might get in the environment in case the protective barriers are compromised. In such a case, spent fuel may pose risk to the environment and human health. Those risks depend on the concentration of the given radionuclide and are measured by the value of potential danger.

The potential danger is called also 'radiotoxicity'. It measures the potential danger a given radionuclide poses if it is ingested (ingestion radiotoxicity) or inhaled (inhalation radiotoxicity) and is defined as the volume of water or air respectively in which the radionuclide should be diluted in order to achieve concentration within the permissible levels. Ingestion radiotoxicity is expressed in $\mathrm{m}^{3}$ of water, while inhalation radiotoxicity is

\footnotetext{
* Corresponding author: ivaylo.naydenov@gmail.com
} 
measured in $\mathrm{m}^{3}$ of air. It is important to emphasise that this interpretation of radiotoxicity (the amount of air or water needed to dilute the radionuclide to allowed levels) show the potential danger of an isotope when there are no barriers impeding its circulation in the environment [2].

Ojovan and Lee [2] define the ingestion, respectively the inhalation radiotoxicity $H_{i}(t)$ of the $i$-th radionuclide as:

$$
H_{i}(t)=\frac{C_{i, 0} \cdot e^{-\lambda_{i} \cdot t}}{I L_{i}} \cdot V,
$$

where $C_{i, 0}$ is the initial concentration of the $i$-th radionuclide, $i$ is the decay constant of the $i$-th radionuclide, $t$ is time, $I L_{i}$ is the values of maximum permissible concentration or intervention level of the $i$-th radionuclide, and $V$ is the volume of water (for ingestion radiotoxicity) or air (for inhalation radiotoxicity) needed to dilute the $i$-th radionuclide's concentration to permissible level.

Spent fuel radiotoxicity has been a subject for research for several decades. Some earlier analysis of long term uranium and MOX spent fuel radiotoxicity can be found in [3]. Over the years the focus has been on evaluating and diminishing long-term radiotoxicity (tens of millions of years after discharge) [4], especially in the case of minor actinides' partitioning and transmutation [5,6] and most recently on thorium fuel usage [7]. The current paper examines the radiotoxicity evolution in the case of a reference pressurised water reactor (PWR) that uses commercial nuclear fuel.

\section{Objective and input data}

The main objective is to carry out a comparative analysis of once trough cycle and closed fuel cycle that uses MOX, in order to evaluate the effect of fuel cycle closure on long-term inhalation and ingestion radiotoxicity. The effect of spent fuel reprocessing has also been analysed. The assessed fuel cycle options are presented on Figure 1. The needed calculations have been carried out using the code ORIGEN. The code uses an exponential matrix method for solving Bateman's equations and has built-in cross-section libraries for different commercially available fuel assemblies. The software generates direct output in terms of radiotoxicity $\left(\mathrm{m}^{3}\right.$ of air per tonne of heavy metal of spent fuel and $\mathrm{m}^{3}$ of air per tonne of heavy metal of spent fuel, respectively) after irradiation and decay simulations [8].

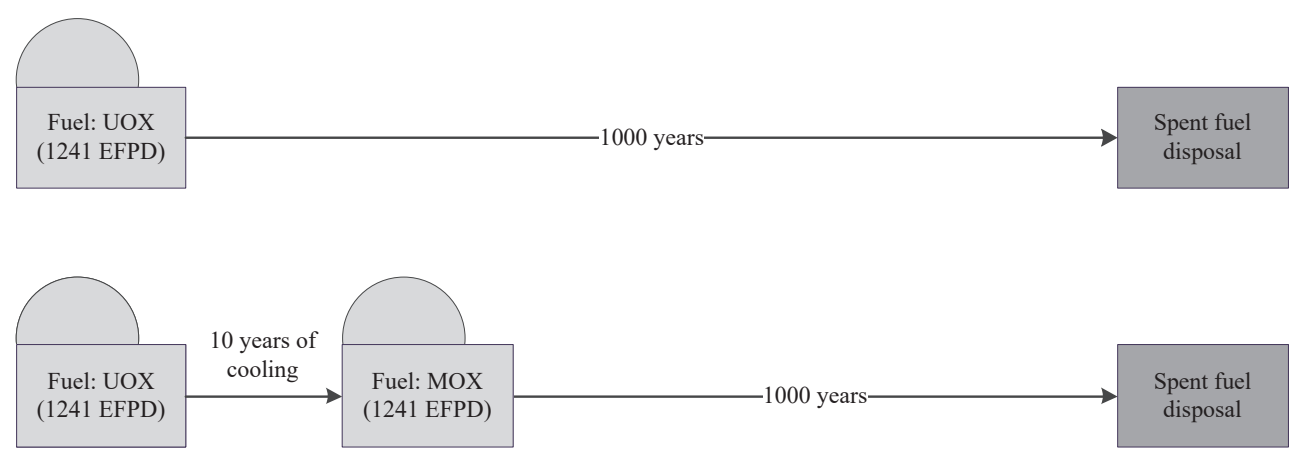

Fig. 1. Schematic representation of the analysed fuel cycles.

In the considered cases a reference pressurised water reactor (PWR) with installed capacity of $1000 \mathrm{MW}$ and gross thermodynamic efficiency of the power unit of $33 \%$ has been used. In the once-through cycle the load is $4.8 \%$ enriched uranium oxide fuel (UOX) 
with design burn-up of 62,000 MWd/tHM. In the closed fuel cycle case, the spent uranium fuel is cooled down for 10 years after discharge before reprocessing, extracting the plutonium and mixed oxide fuel manufacturing.

The selected plutonium weight fraction in the fresh MOX fuel is chosen to be $7 \%$, and the ${ }^{235} \mathrm{U}$ assay in the depleted uranium is set at $0.25 \%$. After irradiation, the spent MOX fuel is cooled down for 1000 years. In order to achieve comparability, the mixed fuel has burn-up of $62,000 \mathrm{MWd} / \mathrm{tHM}$. The fuel cycle length for both uranium and MOX fuels is 1,241.00 EFPD and the calculated thermal load for both fuels is $49.96 \mathrm{MW} / \mathrm{tHM}$. Enrichment, burn-up, plutonium weight fraction, and fuel cycle lengths have been chosen based on data, presented in [9-13], in order to conform to latest developments in nuclear fuels.

The data is used as an input in ORIGEN to calculate the concentrations of plutonium isotopes in the spent fuel for each fuel cycle. These results are shown in Table 1. The obtained isotopic vectors are used to determine the isotopic composition of the fresh MOX (Table 2).

The isotopic vector, shown in Table 1, is the calculated composition of the plutonium, recovered from the irradiated uranium fuel at the $10^{\text {th }}$ year after discharge. Table 2 shows the isotopic composition of the fresh uranium-plutonium fuel manufactured from 7 wt.\% plutonium with the isotopic vector shown in Table 1 and $93 \mathrm{wt} \%$ depleted uranium with 0.25 wt. $\%{ }^{235} \mathrm{U}$. That isotopic composition has been used as input for MOX fuel irradiation calculations.

Table 1. Isotopic vectors of the plutonium, used for mixed fuel manufacturing, wt. \%.

\begin{tabular}{|c|c|c|c|c|c|}
\hline Nuclide & ${ }^{238} \mathrm{Pu}$ & ${ }^{239} \mathrm{Pu}$ & ${ }^{240} \mathrm{Pu}$ & ${ }^{241} \mathrm{Pu}$ & ${ }^{242} \mathrm{Pu}$ \\
\hline $\begin{array}{c}\text { Weight } \\
\text { fraction }\end{array}$ & $3.70 \%$ & $50.97 \%$ & $26.00 \%$ & $9.79 \%$ & $9.55 \%$ \\
\hline
\end{tabular}

Table 2. Fresh MOX isotopic composition, wt. \%.

\begin{tabular}{|c|c|c|c|c|c|c|c|}
\hline Nuclide & ${ }^{238} \mathrm{Pu}$ & ${ }^{239} \mathrm{Pu}$ & ${ }^{240} \mathrm{Pu}$ & ${ }^{241} \mathrm{Pu}$ & ${ }^{242} \mathrm{Pu}$ & ${ }^{238} \mathrm{U}$ & ${ }^{235} \mathrm{U}$ \\
\hline $\begin{array}{c}\text { Weight } \\
\text { fraction }\end{array}$ & $0.26 \%$ & $3.57 \%$ & $1.82 \%$ & $0.69 \%$ & $0.67 \%$ & $92.77 \%$ & $0.23 \%$ \\
\hline
\end{tabular}

In the case of once-through cycle the uranium fuel has been irradiated for 1241 EFPD (4 cycles of 310.25 EFPD) then the spent fuel's isotopic composition change over 1000 years has been simulated. In the case of closed fuel cycle, the uranium fuel has been irradiated for the same cycle length; however, on the tenth year of cooling, the plutonium from the spent fuel is extracted and used for MOX fuel manufacturing. The MOX fuel is then immediately irradiated for 1241 EFPD (4 cycles of 310.25 EFPD) and the spent MOX fuel's isotopic composition change over 1000 years has been simulated (Figure 1).

The evolution of ingestion and inhalation radiotoxicity of the spent uranium and MOX fuels over 1000-year period is evaluated. By substracting the radiotoxicities of uranium and plutonium the results shown in Tables 3 to 6 have been obtained.

The difference between total radiotoxicity and uranium's and plutonium's radiotoxicity shows the residual radiotoxicity of the high-level waste that is generated in the case of reprocessing. The difference is shown for the entire 1000-year period in order to decouple the overall results from the point at which uranium and mixed fuel would be processed. 


\section{Results and analysis}

\subsection{Inhalation radiotoxicity}

A comparison of inhalation radiotoxicity of the spent fuel for the 1000-year cool down is shown on Figure 2. The first 10 years are shown as well in order to clarify the difference between the total radiotoxicity and the radiotoxicity of the radionuclides with major contribution. The difference in the first 10 years is due to some radionuclides with short half-lives that fully decay within the first decade but still contribute to the radiotoxicity. Another observation shows that the inhalation radiotoxicity of uranium fuel (UOX) is higher than that of MOX fuel. That stems from the higher contribution to the UOX radiotoxicity of some major radionuclides, such as curium isotopes and ${ }^{137} \mathrm{Cs}$.
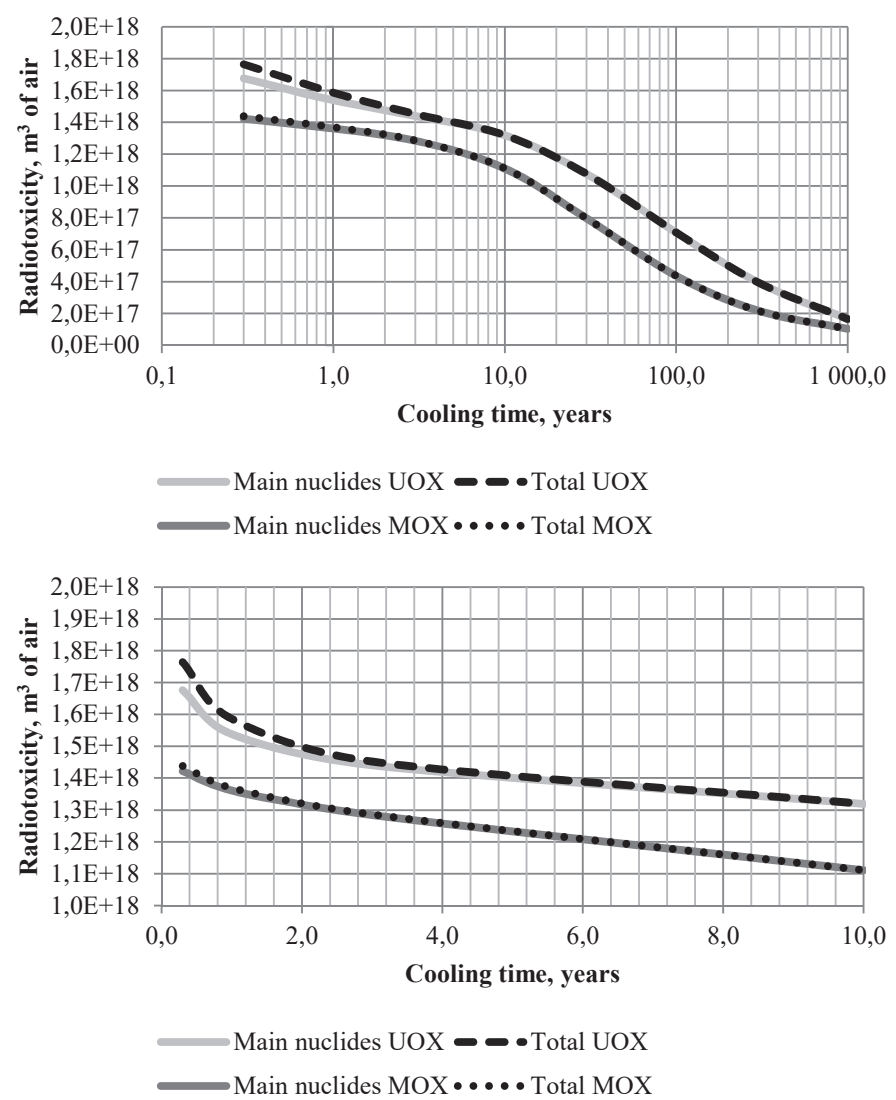

Fig. 2. Inhalation radiotoxicity of a tonne of initial HM spent uranium and MOX fuels for the entire period (above) and for the first 10 years (below).

Some of the radionuclides with major contribution to radiotoxicity found in the uranium fuel include ${ }^{129} \mathrm{I},{ }^{135} \mathrm{Cs},{ }^{90} \mathrm{Sr},{ }^{137} \mathrm{Cs}$, and ${ }^{241} \mathrm{Am}$. The radiotoxicity of ${ }^{129} \mathrm{I}$ and ${ }^{135} \mathrm{Cs}$ is constant over the analysed period, which is due to their very long half-lives $\left(1.57 \cdot 10^{7}\right.$ years and $2.3 \cdot 10^{6}$ years, respectively). ${ }^{90} \mathrm{Sr}$ and ${ }^{137} \mathrm{Cs}$ contribute significantly to the radiotoxicity in the initial period because of their high yields ${ }^{90} \mathrm{Sr}$ - about $6 \% ;{ }^{137} \mathrm{Cs}-$ about $\left.6.2 \%\right)$. However, their radiotoxicity declines over time, due to their relatively short half-lives (28.8 and 30.2 years, respectively). Another important effect is the increase of the radiotoxicity of ${ }^{241} \mathrm{Am}$. That is observed because over time ${ }^{241} \mathrm{Am}$ concentration increases gradually as ${ }^{241} \mathrm{Pu}$ 
decays. ${ }^{242} \mathrm{Cm}$ is a significant contributor to the initial radiotoxicity but due to its short halflife of 160 days its contribution decreases three-fold by the tenth year. Similar effects are observed in spent MOX fuel.

Figure 3 shows a comparison of the total inhalation radiotoxicity of spent fuel and high level waste in the two fuel cycle cases. The figure clearly shows the higher values of $\mathrm{UO}_{2}$ fuel compared to MOX. That is due to the higher yields of major contributors to radiotoxicity, such as ${ }^{137} \mathrm{Cs}$.

The data summarised in Table 3 show the relative contribution of uranium, plutonium, and all the rest of the nuclides (denoted as high-level waste - HLW) in the case of $\mathrm{UO}_{2}$ utilisation. It becomes evident that were the spent fuel reprocessed at the tenth year of storage and plutonium set for MOX manufacturing, the overall radiotoxicity of the residual HLW would have been decreased by around $59 \%$.

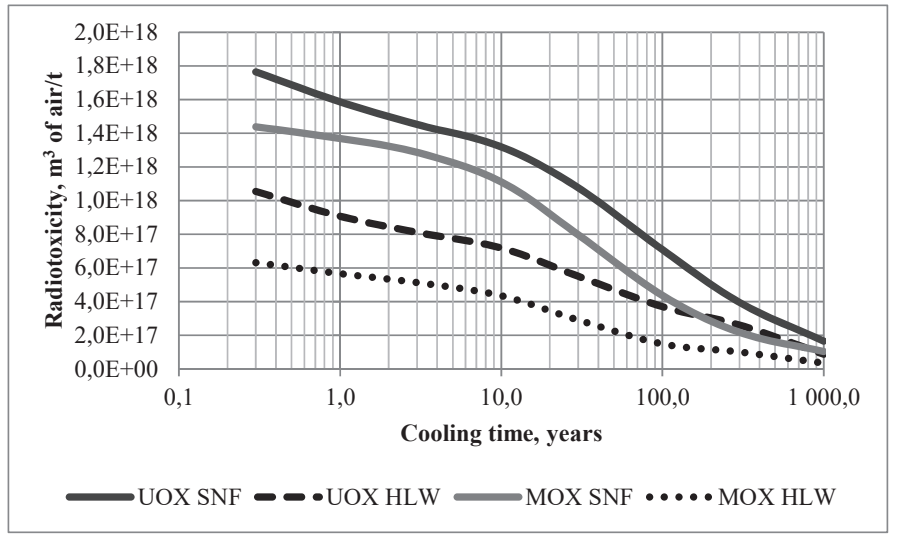

Fig. 3. Inhalation radiotoxicity of spent uranium and MOX fuels and high-level waste (HLW) per tonne of initial HM. HLW radiotoxicity excludes the radiotoxicity of uranium and plutonium.

Table 3. Relative contribution of spent $\mathrm{UO}_{2}$ fuel components to total inhalation radiotoxicity

\begin{tabular}{|c|c|c|c|c|c|c|c|c|}
\hline Year & $\mathbf{0 . 3}$ & $\mathbf{1 . 0}$ & $\mathbf{3 . 0}$ & $\mathbf{1 0 . 0}$ & $\mathbf{3 0 . 0}$ & $\mathbf{1 0 0 . 0}$ & $\mathbf{3 0 0 . 0}$ & $\mathbf{1 0 0 0 . 0}$ \\
\hline Pu & $50.98 \%$ & $56.75 \%$ & $60.13 \%$ & $58.72 \%$ & $55.02 \%$ & $48.07 \%$ & $34.06 \%$ & $47.05 \%$ \\
\hline U & $0.00 \%$ & $0.00 \%$ & $0.00 \%$ & $0.00 \%$ & $0.00 \%$ & $0.00 \%$ & $0.00 \%$ & $0.01 \%$ \\
\hline HLW & $49.02 \%$ & $43.25 \%$ & $39.87 \%$ & $41.28 \%$ & $44.98 \%$ & $51.92 \%$ & $65.94 \%$ & $52.94 \%$ \\
\hline
\end{tabular}

The data summarised in Table 4 show the relative contribution of uranium, plutonium, and all the rest of the nuclides in the case of MOX utilisation. Here the same dependencies as in the case of UOX are observed. If the spent MOX fuel were reprocessed, the radiotoxicity of the HLW would have been diminished by more than $60 \%$.

Table 4. Relative contribution of spent MOX fuel components to total inhalation radiotoxicity

\begin{tabular}{|c|c|c|c|c|c|c|c|c|}
\hline Year & $\mathbf{0 . 3}$ & $\mathbf{1 . 0}$ & $\mathbf{3 . 0}$ & $\mathbf{1 0 . 0}$ & $\mathbf{3 0 . 0}$ & $\mathbf{1 0 0 . 0}$ & $\mathbf{3 0 0 . 0}$ & $\mathbf{1 0 0 0 . 0}$ \\
\hline Pu & $54.96 \%$ & $58.07 \%$ & $59.94 \%$ & $60.91 \%$ & $63.56 \%$ & $65.96 \%$ & $53.82 \%$ & $66.78 \%$ \\
\hline U & $0.00 \%$ & $0.00 \%$ & $0.00 \%$ & $0.00 \%$ & $0.00 \%$ & $0.00 \%$ & $0.00 \%$ & $0.00 \%$ \\
\hline HLW & $45.04 \%$ & $41.93 \%$ & $40.06 \%$ & $39.09 \%$ & $36.44 \%$ & $34.04 \%$ & $46.18 \%$ & $33.22 \%$ \\
\hline
\end{tabular}




\subsection{Ingestion radiotoxicity}

A comparison of the ingestion radiotoxicity of uranium and MOX spent fuels for the 1000year cool down is shown on Figure 4. It can be observed that shortly after discharge the radiotoxicity of spent MOX fuel is higher than the radiotoxicity of the spent uranium fuel. In the course of the cooling, the uranium fuel's radiotoxicity surpasses the radiotoxicity of the MOX. This phenomenon is due to the fact that at the beginning of the cooling in the spent MOX fuel short-lived radionuclides with relatively high contribution to the radiotoxicity are present. If the major contributors are considered, their radiotoxicity is higher in the spent uranium fuel for the entirety of the 1000 -year period. The reason is the higher concentrations of some of the radionuclides with high radiotoxicity, e.g. ${ }^{135} \mathrm{Cs},{ }^{137} \mathrm{Cs}$, ${ }^{90} \mathrm{Y},{ }^{90} \mathrm{Sr}$, and ${ }^{129} \mathrm{I}$, among others.

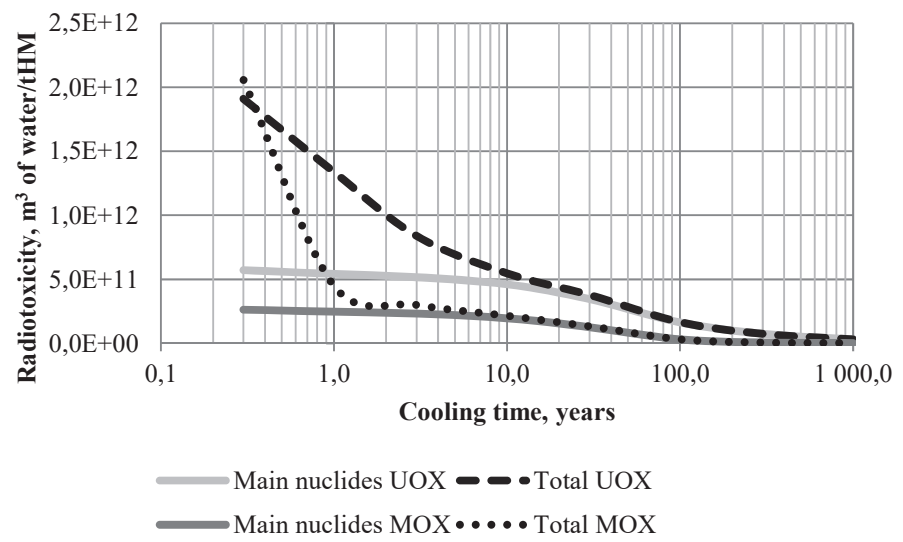

Fig. 4. Ingestion radiotoxicity of a tonne of initial HM spent uranium and MOX fuels.

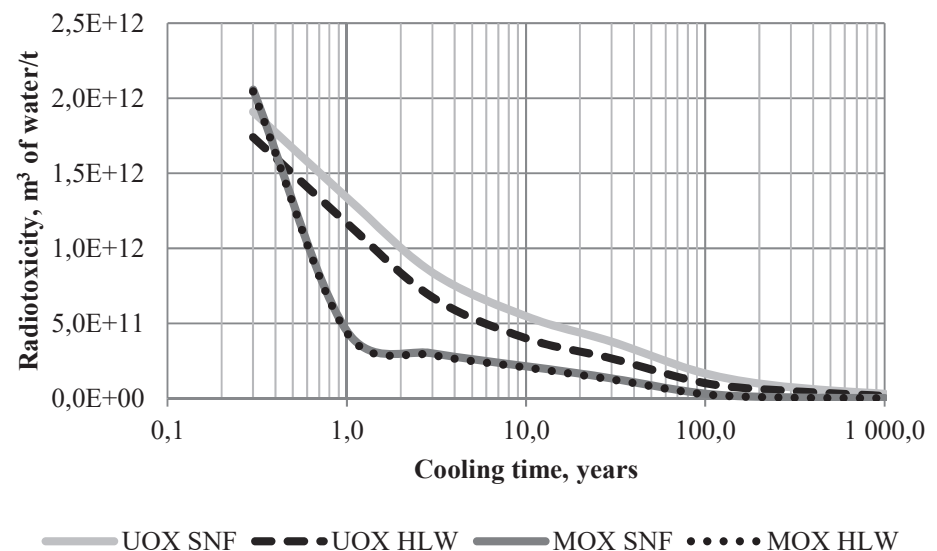

Fig. 5. Ingestion radiotoxicity of a tonne of initial HM spent uranium and MOX fuels and high-level waste (HLW)

The contribution of the main radionuclides to the ingestion radiotoxicity is similar to their contribution to the inhalation radiotoxicity - the values for ${ }^{129} \mathrm{I}$ and ${ }^{135} \mathrm{Cs}$ remain constant, the initial contribution of ${ }^{90} \mathrm{Y},{ }^{90} \mathrm{Sr}$ and ${ }^{137} \mathrm{Cs}$ is significant and ${ }^{241} \mathrm{Am}$ increases over time while a peak occurs. 
Figure 5 shows a comparison of the total ingestion radiotoxicity of spent fuel and high level waste in the two fuel cycle cases. In this case, the HLW carries the majority of the ingestion radiotoxicity; in the case of MOX fuel in the initial years HLW is responsible for almost all of the radiotoxicity. That supports MOX fuel reprocessing, as almost all of the ingestion radiotoxicity would be enclosed in the lower volume of HLW, and simultaneously it would be possible to return the fissile material into the fuel cycle.

The data summarised in Table 5 show the relative contribution of uranium, plutonium, and $\mathrm{HLW}$ in the case of $\mathrm{UO}_{2}$ utilisation. If the spent fuel were reprocessed at the tenth year of storage and plutonium set for MOX manufacturing, the overall radiotoxicity of the residual HLW would have been decreased by around $27 \%$.

Table 5. Relative contribution of spent $\mathrm{UO}_{2}$ fuel components to total ingestion radiotoxicity

\begin{tabular}{|c|c|c|c|c|c|c|c|c|}
\hline Year & $\mathbf{0 . 3}$ & $\mathbf{1 . 0}$ & $\mathbf{3 . 0}$ & $\mathbf{1 0 . 0}$ & $\mathbf{3 0 . 0}$ & $\mathbf{1 0 0 . 0}$ & $\mathbf{3 0 0 . 0}$ & $\mathbf{1 0 0 0 . 0}$ \\
\hline $\mathbf{P u}$ & $8.89 \%$ & $12.69 \%$ & $19.65 \%$ & $26.73 \%$ & $29.57 \%$ & $38.71 \%$ & $33.95 \%$ & $47.00 \%$ \\
\hline $\mathbf{U}$ & $0.00 \%$ & $0.00 \%$ & $0.00 \%$ & $0.00 \%$ & $0.00 \%$ & $0.00 \%$ & $0.01 \%$ & $0.03 \%$ \\
\hline HLW & $91.11 \%$ & $87.31 \%$ & $80.35 \%$ & $73.27 \%$ & $70.43 \%$ & $61.29 \%$ & $66.03 \%$ & $52.97 \%$ \\
\hline
\end{tabular}

The data summarised in Table 6 show the relative contribution of uranium, plutonium, and all the rest of the nuclides in the case of MOX utilisation. Here the same dependencies as in the case of UOX are observed. If the spent MOX fuel were reprocessed, the radiotoxicity of the HLW would be diminished only by about $4.5 \%$.

Table 6. Relative contribution of spent MOX fuel components to total ingestion radiotoxicity

\begin{tabular}{|c|c|c|c|c|c|c|c|c|}
\hline Year & $\mathbf{0 . 3}$ & $\mathbf{1 . 0}$ & $\mathbf{3 . 0}$ & $\mathbf{1 0 . 0}$ & $\mathbf{3 0 . 0}$ & $\mathbf{1 0 0 . 0}$ & $\mathbf{3 0 0 . 0}$ & $\mathbf{1 0 0 0 . 0}$ \\
\hline Pu & $0.55 \%$ & $2.51 \%$ & $3.63 \%$ & $4.42 \%$ & $5.26 \%$ & $12.34 \%$ & $22.37 \%$ & $32.46 \%$ \\
\hline U & $0.00 \%$ & $0.00 \%$ & $0.00 \%$ & $0.00 \%$ & $0.00 \%$ & $0.00 \%$ & $0.01 \%$ & $0.02 \%$ \\
\hline HLW & $99.45 \%$ & $97.49 \%$ & $96.37 \%$ & $95.58 \%$ & $94.74 \%$ & $87.66 \%$ & $77.62 \%$ & $67.53 \%$ \\
\hline
\end{tabular}

The results from Ttables 5 and 6 and Figure 5 suggest that almost all of the ingestion radiotoxicity could be enclosed in the HLW, while the fissile material could be brought back into the nuclear fuel cycle. Since the HLW represents 6-8\% of the mass of the analysed spent UOX and MOX fuels, after reprocessing a much smaller storage would be needed to isolate the majority of the ingestion radiotoxicity.

\section{Conclusions}

The conducted analysis has shown that generally the inhalation and ingestion radiotoxicity of spent uranium fuel is higher than that of spent MOX fuel. In the case of uranium fuel the contribution of plutonium to the radiotoxicity is relatively higher than its contribution in the case of spent MOX fuel. Reprocessing spent UOX fuel and utilizing the plutonium would lead to diminishing the radiotoxicity in the stored material.

On the other hand, in the case of spent MOX fuel, the majority of the radiotoxicity is contributed by materials that would be high-level waste after reprocessing. When ingestion 
radiotoxicity is concerned, almost all of it is contained within the HLW from spent MOX. That means the majority of the radiotoxicity may be contained within smaller storage spaces. The presence of radionuclides with half-lives spanning millions of years $\left({ }^{129} \mathrm{I}\right.$ and ${ }^{135} \mathrm{Cs}$ ) means that the retention times of those materials are virtually infinite. However, reprocessing the spent fuels would mean containing the majority of the radiotoxicity in smaller storage facilities, and by burning the plutonium (the second largest contributor), the rest of the radiotoxicity would be diminished.

\section{References}

1. OECD Nuclear Energy Agency, Trends towards Sustainability in the Nuclear Fuel Cycle (Paris, 2011)

2. M.I. Ojovan, W.E. Lee, An Introduction to Nuclear Waste Immobilisation (Elsevier, 2014)

3. A. G. Elayi, J. P. Schapira, Long-term radiotoxicity of high level wastes and spent fuels produced by light water reactors: impact of burn-up extension and of the use of mixed oxide fuels (Orsay, 1986)

4. D. Westlén, Prog. Nucl. En. 49 (2007)

5. J. Magill, V. Berthou, D. Haas, J. Galy, R. Schenkel, H.-W. Wiese, G. Heusener, J. Tommasi, G. Youinou, Nucl. En. 42, 5 (2003)

6. J.-P. Grouiller, S. Pillon, C. de Saint Jean, F. Varaine, L. Leyval, G. Vambenepe, B. Carlier, J. Nucl. Mat. 320 (2003)

7. A. Zhang, C. Zou, J. Wu, S. Xia, C. Yu, J. Chen, Ann. Nucl. En. 137 (2020)

8. ORNL, Scale: A Comprehensive Modeling and Simulation Suite for Nuclear Safety Analysis and Design, Version 6.1 (Oak Ridge, 2011)

9. Consortium Dicon - Acciona ING., Environmental Impact Assessment Report for Investment Proposal: Building A New Nuclear Unit of the Latest Generation at the Kozloduy NPP Site, Chapter 2 (Sofia, August 2013)

10. Westinghouse Electric Company, $17 x 17$ Next Generation Fuel (17x17 NGF) Reference Core Report (Monroeville, PA, United States, 2011)

11. Framatome Inc., MOX Fuel Design Report (Lynchburg, VA, United States, 2002)

12. F. Courtin, Etude de l'incinération du plutonium en REP MOX sur support d'uranium enrichi avec le code de simulation dynamique du cycle CLASS (Ecole nationale supérieure Mines-Télécom Atlantique, Nantes, 2017)

13. OECD Nuclear Energy Agency, Plutonium Management in the Medium Term (Paris, 2003) 